\title{
Physico-chemical properties of peatland located in the impact zone of municipal landfill
}

\author{
Oksana Telak ${ }^{1}$, Vasyl Popovych ${ }^{2, *}$, Oleh Zachko ${ }^{2}$ and Kateryna Korol $^{2}$ \\ ${ }^{1}$ Main School of Fire Service, 01-629, 52/54 Slowackiego str., Warsaw, Poland \\ ${ }^{2}$ Lviv State University of Life Safety, 79000, 35 Kleparivska str., Lviv, Ukraine
}

\begin{abstract}
The results of studies of peat located in the impact zone of municipal landfill are presented. It is established that according to the peat genetic horizons profile the distribution of the mobile fractions of heavy metals is manifested in a gradual decrease with depth. The content of heavy metals (manganese, copper, zinc, lead, cobalt, mercury) in the peat does not exceed the MAC, except for cadmium, which is spread by waste from the landfill. The source of cadmium in landfills is waste containing lacquers and paints, fluorescent lamps, batteries etc. Cadmium sulfide is the basis for yellow paints used in vehicle dyeing, textile production, soap making. Peat is characterized as very poor in micromycetes distribution. Some micromycetes detected are indicators of high mineral content and low heavy metal content. Analysis of peat micromycetes by growth rate showed that the slowest growing micromycetes owns the largest proportion - 70\%. The distribution by color showed that dark-colored micromycetes of the Moniliaceae, characterized by toxicity, predominate. According to the humus reserve, peat is slightly humus. It is not recommended to use such peat for crop cultivation. Instead, peat can be a source of fuel under conditions of industrial development and compliance with existing rules and state standards.
\end{abstract}

\section{Introduction}

Edaphotope impacts significantly on the development of phytocenoses. Numerous studies of edaphotopes of man-made landscapes are conducted in Ukraine. In anthropogenic landscapes edaphotop is a technogenically formed, spatially restricted biofossil system that is in constant development under the influence of soil formation factors [1]. Peatlands that are in the impact zone of landfill represent a significant man-made hazard.

In the paper [2] the investigation of peatlands located in the impact zone of landfill is presented. It is established that groundwater of peatlands, which are in the impact zone of the landfill are classified as "dangerous" and "extremely dangerous". The major contributors to peat contamination are substances of the 1st ( $\mathrm{Hg}, \mathrm{As}, \mathrm{Zn}), 2 \mathrm{nd}(\mathrm{Cu}, \mathrm{Co})$ and 3 rd substance hazard categories (petroleum products). These also show that the greatest pollution occurs from the eastern side of the landfill, where the pollutants are carried out by filtration waters in the direction of groundwater flow. The investigation of the occurrence of rare earth elements in peat is presented in [22]. It is established that from 40 to $80 \%$ of 
the total amount of REE in peat is water-soluble substances, $10-30 \%$ of REE is concentrated in humic acids.

Peatlands are divided into two groups: upper (mossy) and lowland (sedge-reed). Upper peat accumulates more organic matter and lowland is richer in the mineral nutrition of plants [3]. The mineral composition of peat is given in Table. 1.

Table 1. Composition of peat of different origin.

\begin{tabular}{|l|c|c|c|c|c|c|}
\hline \multirow{2}{*}{ Peat } & \multirow{2}{*}{$\mathbf{p H}$} & \multicolumn{5}{|c|}{ Content (\%) in a dry matter } \\
\cline { 3 - 7 } & & $\begin{array}{c}\text { Organic } \\
\text { matter }\end{array}$ & Ash & $\begin{array}{c}\text { Nitrogen } \\
\text { (organic) }\end{array}$ & $\mathbf{P}_{\mathbf{2}} \mathbf{O}_{\mathbf{5}}$ & $\mathbf{K}_{\mathbf{2}} \mathbf{O}$ \\
\hline Upper & $2.8-3.6$ & $95-98$ & $2-5$ & $0.8-1.4$ & $0.05-0.14$ & $0.03-0.10$ \\
\hline Lowland & $4.8-5.8$ & $59-90$ & $\geq 10$ & $1.5-3.4$ & $0.25-0.60$ & $0.10-0.20$ \\
\hline
\end{tabular}

Basing on the results of investigation of peat deposits [21] it is possible to classify them by the degree of deposit drainage. A new approach to the use of the term "surface reservoirs" for peat deposits is proposed and changes in the hydrophysical properties of peat micro- and macrosystems in the drainage process are analyzed.

In peatlands, micromycetes develop. Soil microscopic fungi are very sensitive to changes in soil properties, so they may be an indicators of its condition [4]. Micromycetes are not only an integral component of terrestrial and aquatic biocoenoses, which control a wide range of biosphere functions, but also the main group of microorganisms, which are responsible for both the synthesis and destruction of humic substances in soil. The manmade impact on the environment and the rapid development of nanotechnology makes the problem of investigation of micromycetes interaction with natural organic matter urgent and up-to-date [5].

The main feature of micromycetes is that they dominate in the soil microbiota. They are the most species group of microorganisms involved in the mineralization of organic plant and animal remains and humus formation. The decomposition rate of organic matter is determined by such factors as the chemical composition of the substrate, the efficiency of the microorganisms nitrogen supply, the composition of the microbial environment and environmental conditions. At aerobic conditions fungi are able to decompose even complex polymeric compounds, such as lignin, unlike other microorganisms that are more conducive to the mineralization of low molecular weight organic compounds [6]. Some soil fungi are able to decompose humus and use it as a source of nitrogen and/or carbon. In this case micromycetes are involved not only in the process of degradation of humic substances, but also in their formation [7].

Thus, investigation of edaphotopes of man-made landscapes, including peatlands located in the impact zone of municipal landfill, is relevant in terms of reducing of their impact and returning to national economic use.

\section{Materials and Methods}

Peatland is located within $2 \mathrm{~km}$ to the east of the foot of the Lviv municipal landfill (Lviv, Ukraine). This deposit was one of the largest in the world on peat reserves. After the Second World War the local population produced peat briquettes manually for heating their homes. As a result, peatlands lost a significant part of their capacity. At the present moment, agricultural products are grown on peatlands. Though it is forbidden because of the peat deposition of pollutants, including filtrate from the landfill.

In order to investigate the impact of hazardous factors of landfill on the formation of the peatland profile, we have chosen the test areas where the peat samples were taken 
according to genetic horizon and mycological, agrochemical analyzes, as well as analyzes on the content of nutrient minerals and heavy metals were carried out.

The description of the genetic horizons and the classification of soils were carried out according to [20]. Sampling was performed in accordance with the requirements of the relevant national standards and guidelines. Physicochemical studies of edaphotopes within soil horizons were carried out using the methods of Arinushkina [13], Mineev [14]. Namely the nitrate form of nitrogen was determined according to Grandval-Liazhu disulfophenol method, the mobile forms of phosphorus and potassium according to the Machihin and Kirsanov methods, the humus content according to Antonova, Skalabyan, Suchilkina method [15-19]. The results were compared with the maximum allowable concentrations of hazardous substances in peatlands, which are given in the standards - SanPiN 42-128-443387 and "Maximum allowable concentrations of chemicals in soil", List No. 4, rev. Ministry of Health of the USSR from 30.04.82 № 2546-82 [8, 9].

Determination of quantitative and qualitative composition of micromycetes of manmade landfills was performed by sowing of soil suspension from decimal dilutions on wortagar and Chapek agar medium. The cultivation of the samples was carried out at a temperature of $+26-28^{\circ} \mathrm{C}$. Isolated samples were investigated by a microscope "MBI- 6 " according to the method adopted to mycological studies (I.A. Dudka, S.P. Vasser, E.A. Elanskaya, 1982). The investigation of isolated fungi was carried out according to conventional determinants (N.M. Pidoplichko, A.A. Milko, 1971; M. B. Ellis, 1993).

Statistical data processing was performed according to conventional methods, correlation analysis using Microsoft Excel 2010.

\section{Results and Discussion}

The interest to investigation of the physicochemical properties of peat located in the impact zone of landfill, is based on the fact that the peat is:

- the major component of the landscape, in which various biogeochemical and migration processes occur, and

- $\quad$ a natural sorbent for various substances in ecosystems;

- $\quad$ a destruction level index of the natural ecosystem.

In the description of deep peatland it was found that the content of heavy metals in the surface layer T1 is much higher than in the genetic horizon T2. However, the indicators of manganese, copper, zinc and lead in the investigated horizons do not exceed the maximum allowable concentrations (Fig. 1).

Considering the abovementioned data, it can be affirmed that the cobalt content in peatlands does not exceed the MAC of $5 \mathrm{mg} / \mathrm{kg}$ [8]. The mercury content is 250 times lower than the MAC of $2 \mathrm{mg} / \mathrm{kg}$ [9]. The cadmium content is twice lower than the MAC of $0.7 \mathrm{mg} / \mathrm{kg}$. In general, the presence of this toxicant in the soil in amount of $0.5 \mathrm{MAC}$ is a negative fact. Waste containing lacquers and paints, fluorescent lamps, batteries etc. is the source of cadmium in landfills. Cadmium selenide is the basis of yellow paints used in vehicle dyeing, textile production, soap making. Cadmium selenide is used as a red dye. Also, cadmium is used in semiconductor materials, cryogenic technology, lead-cadmium and mercury-cadmium battery cells, and anti-corrosion metals coating [10].

The distribution of mobile fractions of heavy metals by the soils profile is manifested in a gradual decrease of them with depth. 

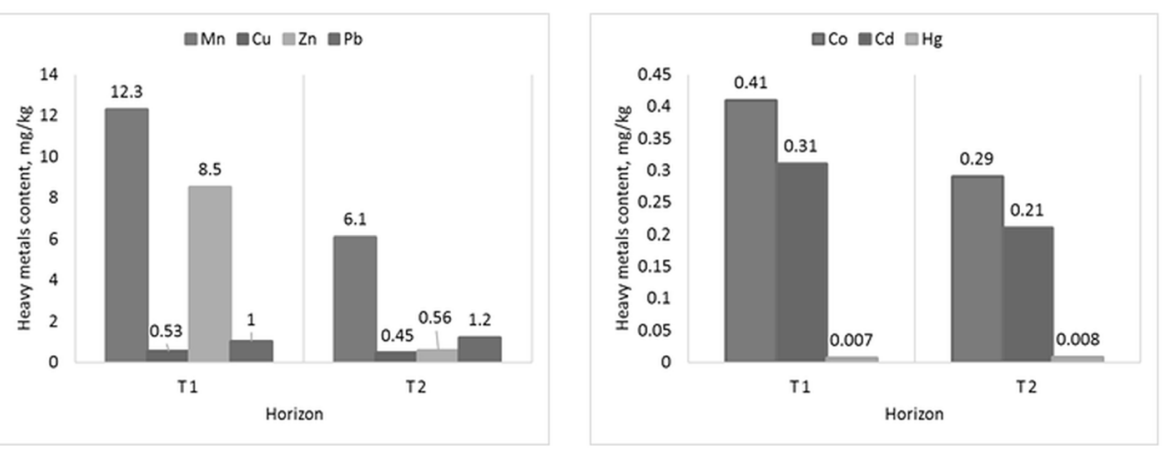

Fig. 1. Heavy metals distribution in investigated genetic horizons .

The investigation of physico-chemical composition of genetic horizons have shown that peatlands have a significant supply of nitrogen $(56.05 \mathrm{mg} / 100 \mathrm{~g})$ and potassium $(58.5$ $\mathrm{mg} / 100 \mathrm{~g})$ nutrients and low content of humus $(2.06 \%)$ and nitrogen fertilizers $(0.84$ $\mathrm{mg} / 100 \mathrm{~g}$ ). According to the humus reserve, peat is slightly humous.

An analysis of the micromycetes activity on the landfills showed that in the $\mathrm{T}_{1}$ horizon peatlands the families of Mucoraceae, Moniliaceae, Tuberculariaceae are distributed. The total number of micromycetes was determined by the method of sowing on the Chapek acidified nutrient medium (the number of colony forming units - CFU per $\mathrm{g}$ of soil). This index was quite low compared to the background values. In general, according to the scale of DG Zvyagintsev [11], peatlands are characterized as very poor in the micromycetes distribution level.

In soil section \# 1, 10 micromycetes species were found. Among them representatives of families: Mucoraceae - 1 pc.; Moniliaceae - 5 pcs.; Tuberculariaceae - 4 pcs. (Table 2).

Table 2. Micromycetes species composition in the peatland

\begin{tabular}{|c|c|}
\hline Type & $\begin{array}{l}\text { Number of fungi propagules per } 1 \mathrm{~g} \text { of soil, } \\
\text { (thous.) } \times 10^{4}\end{array}$ \\
\hline \multicolumn{2}{|c|}{ Division Zygomyceta } \\
\hline \multicolumn{2}{|c|}{ Class Zygomycetes } \\
\hline \multicolumn{2}{|c|}{ Family Mucoraceae } \\
\hline Monilia sp. & 9 \\
\hline \multicolumn{2}{|c|}{ Class Hyphomycetes (Deuteromycetes) } \\
\hline \multicolumn{2}{|c|}{ Family Moniliaceae } \\
\hline Aspergillus ustus & 17 \\
\hline Aspergillus nidulans & 21 \\
\hline Aspergillus fischeri var.spinosus & 15 \\
\hline Aspergillus clavatus & 21 \\
\hline Aspergillus thomii & 12 \\
\hline \multicolumn{2}{|c|}{ Family Tuberculariaceae } \\
\hline Penicillium brevicompactum & 16 \\
\hline Trichoderma lignorum & 24 \\
\hline Fusarium culmorum & 21 \\
\hline Fusarium expansum & 25 \\
\hline
\end{tabular}

It should be noted that the presence of the Fusarium micromycetes in the edaphotope is the proof of a high content of minerals and a low content of heavy metals. This genus of micromycetes was discovered by researchers [12] in a landfill filtrate during the study of a 
biosorption multilayer filter. Micromycetes of the genus Fusarium were actively involved in the formation of the filter biofilm.

In general, the analysis of peat micromycetes by growth rate showed that the slowest growing micromycetes are up to $70 \%$, and the fast growing - 30\%. Undoubtedly, such an indicator of the fungi growing rate is negative, since it causes the inhibition of the succession development. The color distribution showed that dark-colored micromycetes of the Moniliaceae family, characterized by toxicity, predominate.

\section{Conclusion}

It is established that the content distribution of mobile forms of heavy metals, according to the genetic horizons profile for peat $\left(T_{1}, T_{2}\right)$, manifests in a gradual decrease with depth. The content of heavy metals in peat does not exceed the MAC, except for cadmium, which is spread by waste from landfill.

In general, peatlands are characterized as very poor in micromycetes distribution. Some detected micromycetes (Tuberculariaceae family) are indicators of high mineral content and low heavy metal content.

Investigation of the physical and chemical composition of the genetic horizons have shown that peatlands have a significant supply of nitrogen $(56.05 \mathrm{mg} / 100 \mathrm{~g})$ and potassium $(58.5 \mathrm{mg} / 100 \mathrm{~g})$ nutrients and low humus content $(2.06 \%)$. According to the humus reserve, peat is slightly humous. It is not recommended to use such peat for crop cultivation. Conversely, peat can be a source of fuel under conditions of industrial development and compliance with existing rules and state standards.

\section{References}

1. I. Kh. Uzbek, T. I. Halahan, Soil Sci., 1-2:13, 108-113 (2012)

2. N. S. Larionov, Ecological and analytical assessment of the components of the environment in the impact zone of places of disposal of municipal waste (ASU, Arhangelsk, 2009)

3. A. N. Orlova, A. A. Sudarkina, I. I. Evseeva, Studying of the optional course "Chemistry in Agriculture" (Prosveshenie, Moscow, 1981)

4. T. G. Mirchink, Soil mycology (MSU, Moscow, 1988)

5. V. A. Terekhova. Micromycetes in the environmental assessment of aquatic and terrestrial ecosystems (Nauka, Moscow, 2007)

6. L. V. Gribanova. The mycology fundamentals (MSU, Moscow, 2005)

7. V. F. Selevtsev, Soil humus and its properties (USU, Yekaterinburg, 2008)

8. Sanitary Rules and Regulations 42-128-4433-87

9. Maximum allowable concentrations of chemicals in the soil, list 4, of 30.04.82 \# 254682

10. V. N. Lyubomirova, Comprehensive assessment of the environmental hazard of unauthorized landfills in rural areas of the Ulyanovsk region (USTU, Ulyanovsk, 2013)

11. D. G. Zvyagintsev, Methods of soil microbiology and biochemistry (MSU, Moscow, 1991)

12. Ya. S. Shishkin, Reducing the environmental effect of landfills on hydrosphere at the final stages of the life cycle (NUTU, Perm, 2007) 
13. E. V. Arinushkina, Guidance on chemical analysis of soils (MSU, Moscow, 1970)

14. Tutorial on agrochemistry: work book (MSU, Moscow, 2001)

15. DSTU 4114-2002

16. DSTU 4405:2005

17. GOST 26488-85

18. International Standard ISO 10390:2007

19. GOST 26213-91

20. N.K. Krupsky, Atlas of soils of the Ukrainian SSR (Urozhai, Kiev, 1979)

21. O. Misnikov, E3S Web Conf. 105, 01010 (2019)

22. S.I. Arbuzov et al. J. Geochem. Explor., 184(A), 40-48 (2018) 